\title{
Surface Microstructure and Properties of Nodular Cast Iron Rapidly Solidified by Laser Surface Melting*1
}

\author{
Reita Murakami ${ }^{1, * 2}$, Ichihito Narita ${ }^{2}$ and Hirofumi Miyahara ${ }^{1, * 3}$ \\ ${ }^{1}$ Department of Materials Science and Engineering, Kyushu University, Fukuoka 819-0395, Japan \\ ${ }^{2}$ Faculty of Education, Osaka Kyoiku University, Kashiwara 582-8582, Japan
}

Ferrite-matrix nodular cast iron has been modified by a laser surface melting process to develop its microstructure and to improve the surface hardness. A YAG laser beam was irradiated on a substrate and the microstructure of the melted layer was investigated as a function of the pulse energy at a constant specimen travel speed. The surface of the specimen is melted and then rapidly solidified up to a depth of $100 \mu \mathrm{m}$ order. The melted depth increases with increasing pulse energy. In addition, the ferrite-phase matrix around the spheroidal graphite in cast iron preferentially melts because several alloying elements are segregated at the ferrite/graphite interface. The solidified layer consists of three distinctive parts: first, a martensite phase appears in the vicinity of the melted/unmelted substrate interface, then single-phase austenite crystallized on the martensite phase, and finally a ledeburite-austenite hybrid structure unidirectionally solidified from the substrate towards the surface. A cooling rate from 0.3 to $2.4 \times 10^{4} \mathrm{~K} / \mathrm{s}$ is estimated from the austenite primary dendrite arm spacing under our experimental conditions. The micro-Vickers hardness was also examined in relation to the area fractions of the ferrite, austenite and cementite phases. The Vickers hardness varies from 600 to $900 \mathrm{HV}$ in the solidified layer, whereas the initial substrate shows $200 \mathrm{HV}$. This tendency for the hardness to increase is estimated from the hardnesses and volume fractions of the soft austenite and hard ledeburite. [doi:10.2320/matertrans.T-M2018831]

(Received January 31, 2018; Accepted May 25, 2018; Published August 25, 2018)

Keywords: nodular cast iron, laser surface melting, martensite, austenite, ferrite, ledeburite, rapid solidification, dendrite, hardness

\section{Introduction}

Cast iron has been used as a raw material of complicated products because of its many advantages such as high castability due to its high fluidity and few cast defects due to the crystallization of the graphite contained in cast iron. Since spheroidal graphite provides good machinability via a lubricating effect, it has been used for the bed, cam and cylinder parts of machine tools. ${ }^{1-3)}$ In addition, optimization of the heat treatment of the matrix microstructure has enhanced the applicability of cast iron. For example, ferrite is selected for applications involving impact and requiring toughness. ${ }^{1)}$ However, the hardness of the ferrite matrix is insufficient to provide abrasion resistance, and the applicability of ferrite-matrix cast iron is limited under severe wear conditions.

To improve the surface hardness of ferrite- or perlitematrix cast iron, induction hardening or laser quenching is generally performed. ${ }^{4-8)}$ However, the difficulty of increasing the hardness has been reported for ferrite-matrix spheroidalgraphite cast iron. ${ }^{7,8)}$ On the other hand, a laser surface melting process and a laser glazing process have been developed. ${ }^{6}$ These techniques have advantages including a local grain refinement, a high cooling rate of $10^{3} \sim 10^{6} \mathrm{~K} / \mathrm{s}$, and the formation of a metastable phase..$^{9-11)}$ In addition, these melting techniques can be used to design the alloying composition at the surface of a specimen by applying another alloying powder. The surface characteristics of cast iron may be improved by rapid solidification after laser irradiation with or without adding an element ${ }^{1)}$ because graphite generally changes into hard carbide. Also, a few improvements have

\footnotetext{
${ }^{* 1}$ This Paper was Originally Published in Japanese in J. Japan Thermal Spray Society 54 (2017) 12-17.

${ }^{* 2}$ Graduate Student, Kyushu University

${ }^{* 3}$ Corresponding author, E-mail: miyahara@zaiko.kyushu-u.ac.jp
}

been reported for the laser surface melting process for steel or cast iron. ${ }^{3,9,12)}$

Therefore, in this study, the laser surface melting process was performed on spheroidal graphite ferrite-matrix cast iron while providing a high-power local energy to induce rapid solidification. The microstructural development of the specimen surface was investigated and the improvement of the hardness was evaluated in relation to the solidified microstructure without the addition of an alloying element.

\section{Experimental Procedure}

Commercially available spheroidal graphite cast iron (Fe-3.75 mass \% C (hereinafter mass \% is abbreviated to \%)$1.64 \% \mathrm{Si}-0.23 \% \mathrm{Mn}-0.014 \% \mathrm{P}-0.005 \% \mathrm{~S}-0.029 \% \mathrm{Mg}$ ) was prepared as the substrate material. The carbon equivalent (C.E. $=\mathrm{C} \%+1 / 3 \mathrm{Si} \%)$ of the specimen was controlled at $4.3 \%$. Its microstructure consisted of $91 \mathrm{vol} \%$ ferrite and $3 \mathrm{vol} \%$ pearlite with a uniform distribution of $6 \mathrm{vol} \%$ spheroidal graphite. Specimens were machined to dimensions of $40 \mathrm{~mm} \times 25 \mathrm{~mm} \times 5 \mathrm{~mm}$ and subjected to mirror-surface polishing by emery papers and diamond paste.

The laser irradiation equipment was composed of a YAG laser oscillator (Mechatro Japan, LR-300) and a stainless-steel chamber including an electric stage and an atmosphere adjustment system. First, a specimen was placed in the chamber in an Ar gas flow of $1 \mathrm{~L} / \mathrm{min}$. Then, the laser irradiated the $40 \mathrm{~mm} \times 25 \mathrm{~mm}$ surface of the specimen with the pulse duration $(2.0,2.5,4.0$ and $5.0 \mathrm{~ms})$, pulse energy ( 5 , $8,10,12$ and $15 \mathrm{~J})$ and pulse frequency $(20,25,30,40$ and $50 \mathrm{~Hz}$ ) systematically changed using a laser beam with a spot diameter of $2.0 \mathrm{~mm}$. The pulse energy and mean laser power are respectively defined by eqs. (1) and (2) as shown in Fig. 1.

$$
\begin{aligned}
& E_{P}=P_{P} \times t_{P} \\
& P_{\text {mean }}=E_{P} \times f
\end{aligned}
$$




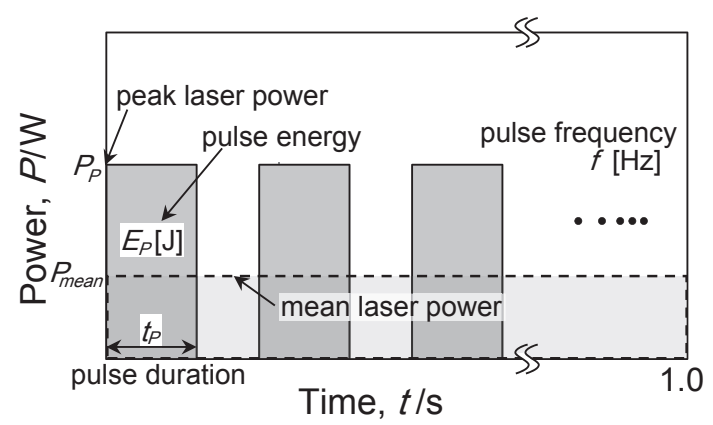

Fig. 1 Schematic illustration of definitions of pulse energy, peak laser power, mean laser power and pulse duration.

Here, $E_{P}$ is the pulse energy [J], $P_{P}$ is the peak laser power [W], $t_{P}$ is the pulse duration [s], $P_{\text {mean }}$ is the mean laser power [W] and $f$ is the pulse frequency $[\mathrm{Hz}]$. In a preliminary experiment, the laser beam was irradiated without any movement of the specimen. In this case, the energy density is given by

$$
Q=\frac{E_{P} \times n}{\pi r^{2}},
$$

where $Q$ is the energy density $\left[\mathrm{J} / \mathrm{m}^{2}\right], n$ is the number of laser shots and $r$ is the laser beam spot diameter $(r=2.0 \mathrm{~mm}$ in this experiment). Then, the specimen was melted while moving the specimen at a stage speed of $1.0 \mathrm{~mm} / \mathrm{s}$. In this case, the energy density is given by

$$
Q=\frac{P_{\text {mean }}}{2 v r},
$$

where $v$ is the specimen travel speed $[\mathrm{m} / \mathrm{s}]$. The solidified specimen was cut perpendicularly and a longitudinal section was polished by an emery papers and diamond paste to obtain a mirror-finished surface. Then the specimen etched by $5 \%$ nital etchant (ethanol - 5\% $\mathrm{HNO}_{3}$ ), hydrochloric acid picric acid alcoholate (ethanol - $1 \% \mathrm{C}_{6} \mathrm{H}_{3} \mathrm{~N}_{3} \mathrm{O}_{7}-15 \% \mathrm{HCl}$ ) and a picric acid soda alkaline solution (water - $2 \% \mathrm{C}_{6} \mathrm{H}_{3} \mathrm{~N}_{3} \mathrm{O}_{7}-$ $25 \% \mathrm{NaOH}$ ). The surface microstructure was observed by an optical microscope and a SEM (Zeiss, ULTRA55), and the cooling rate was estimated from the dendrite arm spacing and eutectic lamella spacing. The hardness along a longitudinal section was also measured at intervals of $20 \mu \mathrm{m}$ from the surface to the substrate using a micro-Vickers hardness tester (Akashi, MVK-H1) at a load of $25 \mathrm{gf}$ with a holding time of $10 \mathrm{~s}$. The obtained hardness was evaluated in relation to the area fractions of the ferrite, austenite and cementite phases by image analysis software.

\section{Results and Discussion}

\subsection{Effect of laser irradiation conditions on depth of melting}

First, the specimen was melted by 20 shots of the laser at a pulse energy from 5 to $15 \mathrm{~J}$ without moving the specimen to determine the effect of the laser conditions on the solidified microstructure. Before the laser irradiation, spheroidal graphite was distributed throughout the ferrite matrix as shown in the center and lower part of the substrate in Fig. 2. The specimen surface melts and the graphite disappears upon
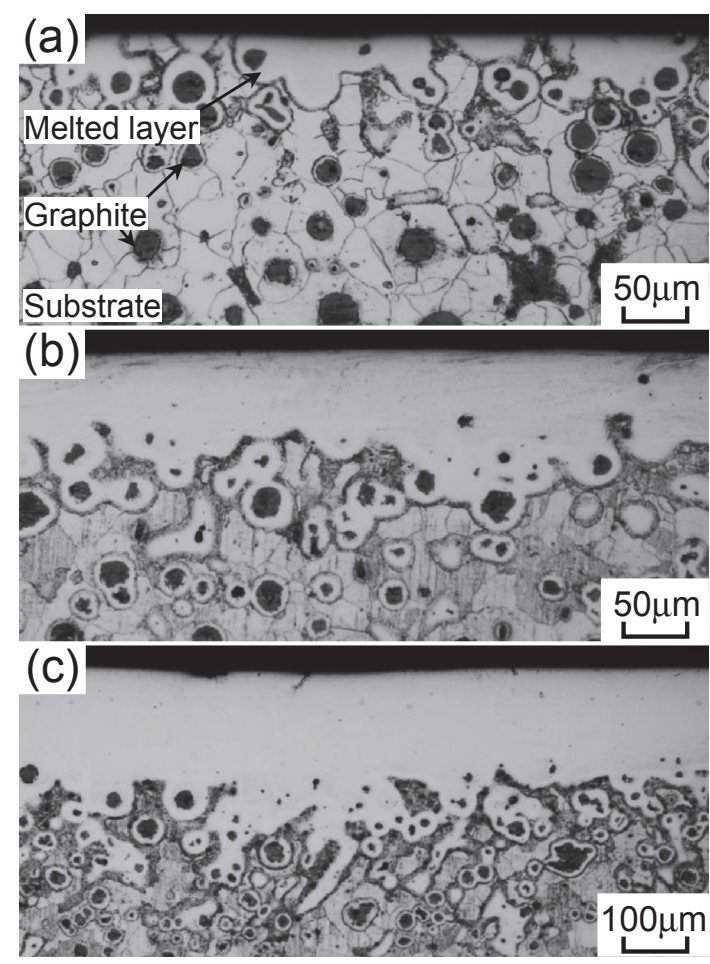

Fig. 2 Longitudinal cross section of the layer meted by 20 laser shots with a pulse energy of (a) $5 \mathrm{~J}$, (b) $10 \mathrm{~J}$ and (c) $15 \mathrm{~J}$ and a pulse duration of $5.0 \mathrm{~ms}$.

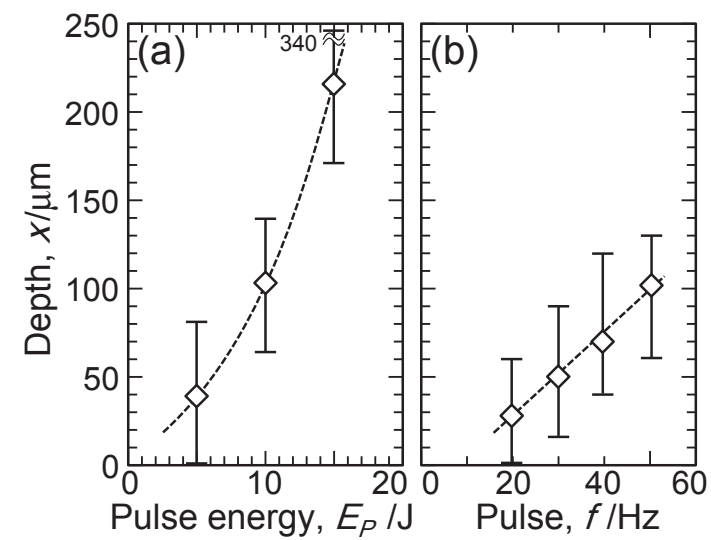

Fig. 3 Effects of (a) pulse energy and (b) pulse frequency on the melted depth for 20 shots with a pulse duration of $5.0 \mathrm{~ms}$.

the laser irradiation. An unmelted region remains at the surface of the specimen subjected to a pulse energy of $5 \mathrm{~J}$ (Fig. 2(a)), but the melted depth increases with increasing pulse energy (Figs. 2(b) and (c)). The graphite melts under all laser conditions, and the matrix around the graphite also melts even far from the surface. This is because that the melting point of the matrix around the graphite is reduced by the distribution of the solute element, which segregated during the manufacturing of the substrate. To evaluate the melted depth for laser irradiation conditions, we defined the mean value of the five deepest and five shallowest regions in the melted layer as the representative depth. The effects of the pulse energy and pulse frequency on melted depth are summarized in Figs. 3(a) and (b), respectively. The melted depth increases in proportion to the pulse energy raised to the power 1.63 and in proportion to the pulse frequency. In 

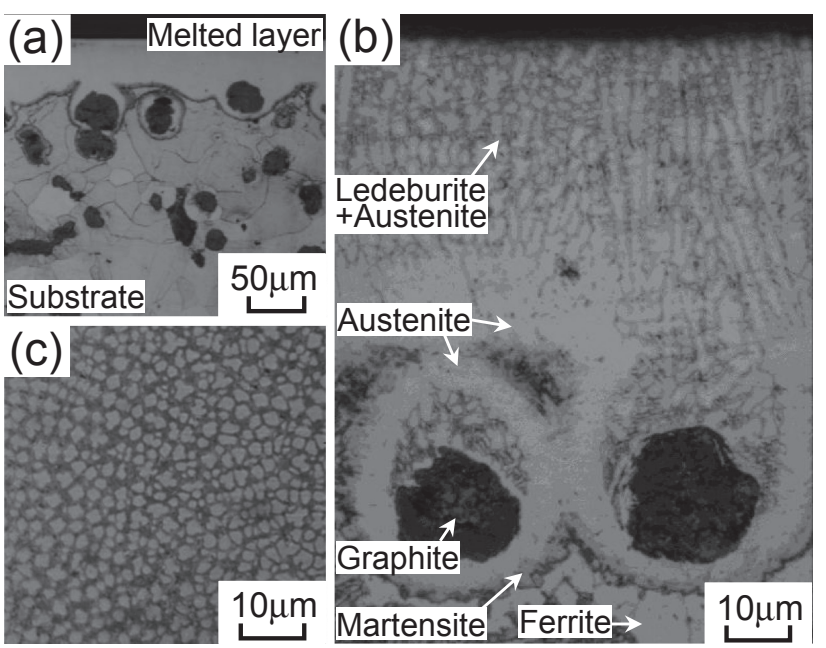

Fig. 4 Longitudinal cross sections of solidified layer at (a) low and (b) high magnification, and (c) transverse cross section of surface melted by a pulse energy of $10 \mathrm{~J}$, a pulse frequency of $25 \mathrm{~Hz}$ and a travel speed of $1.0 \mathrm{~mm} / \mathrm{s}$.

addition, the pulse duration does not have a significant effect in the rage of $2.0-5.0 \mathrm{~ms}$ under our experimental conditions.

\subsection{Analysis of solidified structure and estimation of cooling rate}

On the basis of the preliminary experiment, we fixed the pulse duration to $2.0 \mathrm{~ms}$, the pulse frequency to $25 \mathrm{~Hz}$ and the specimen speed to $1.0 \mathrm{~mm} / \mathrm{s}$, then investigated the effect of the pulse power in the range from 8 to $12 \mathrm{~J}$. The center part of the specimen melts almost uniformly in around $15 \%$ of the dispersion and the matrix around the graphite melts preferentially, as shown in Fig. 4(a). To investigate the microstructure of the melted layer (the white area in Fig. 4(a)) in detail, the specimen was etched by hydrochloric acid picric acid soda alkaline solution. As shown in Fig. 4(b), many phases are observed from the substrate to the surface of the specimen. A martensite layer with a thickness of $\mu \mathrm{m}$ order formed at the melted layer/unmelted substrate interface. Then, the single-phase austenite and a hybrid structure forms on the martensite layer. The hybrid structure is revealed to be a mixture of an austenite phase, which grows in a cellular or dendritic growth regime, and a ledeburite eutectic structure that solidified between the austenite phases as shown in Fig. 4(c). SEM investigation also clearly revealed a ledeburite eutectic structure consisting of an austenite phase and a cementite (Fig. 5). A larger amount of the ledeburite eutectic structure seems to form in the vicinity of the spherical graphite than far from the graphite. This indicates that the melting of the graphite by laser irradiation increases the carbon concentration.

The mean primary austenite dendrite arm spacing is measured to be $2.36 \mu \mathrm{m}$ from Fig. 4(c). The representative arm spacing is measured near the surface because the austenite dendrites grew unidirectionally toward the surface and the number of primary arms did not change significantly at the surface and at the bottom of the specimen. However, the cooling rate is expected to have been affected by the pulse energy. Thus, the primary dendrite arm spacing was measured as a function of the pulse energy as shown in
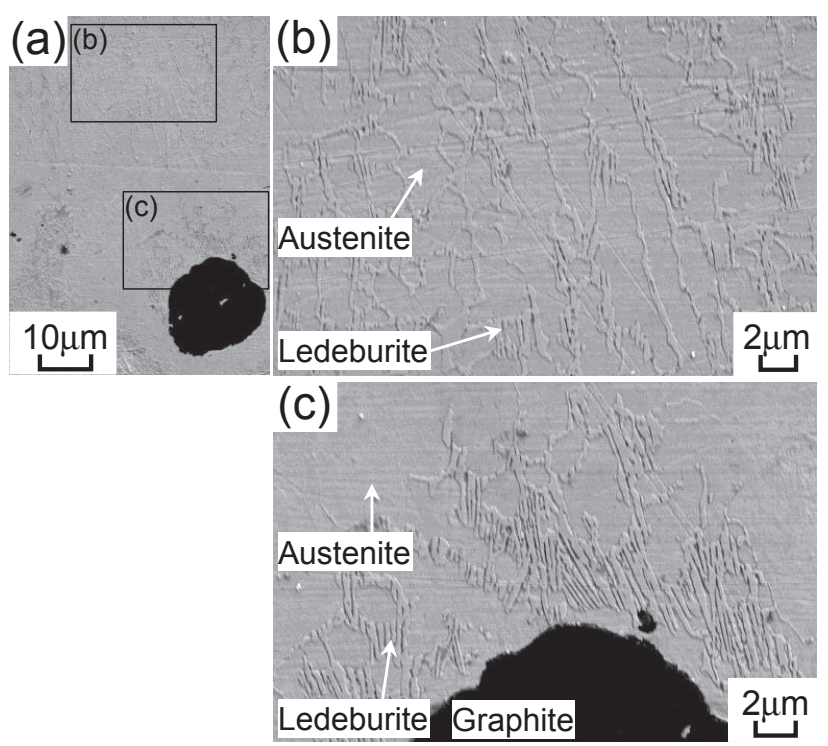

Fig. 5 SEM images of surface layer (a) at low magnification, (b) near the surface and (c) around the graphite in Fig. 4.
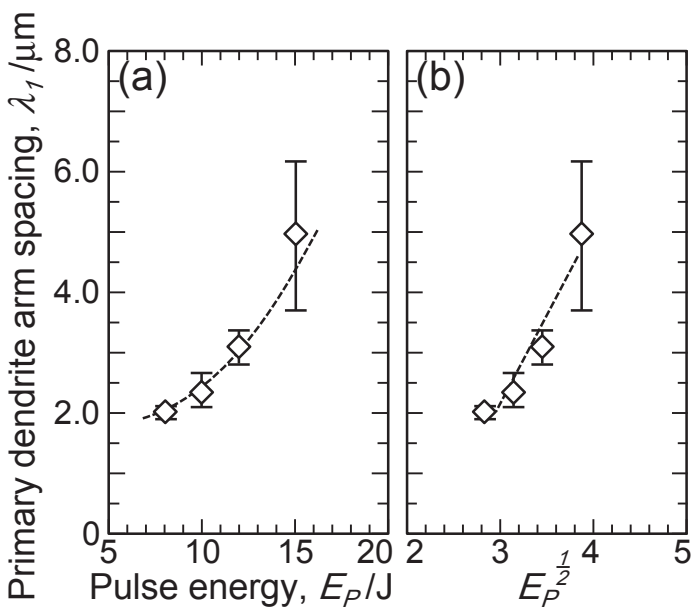

Fig. 6 Effect of the pulse energy on the primary dendrite arm spacing in the vicinity of the specimen surface.

Fig. 6(a). The arm spacing increases in proportion to the pulse energy to the power 1.40 . The lamella spacing of the cementite phase in the ledeburite microstructure is measured to be $0.31 \mu \mathrm{m}$. The relationship between the primary arm spacing $\left(\lambda_{1}\right)$ and solidification parameters such as the cooling rate $(R)$, growth velocity $(V)$, temperature gradient $(G)$ and initial composition $\left(C_{0}\right)$ has been discussed, and it is reported that $\lambda_{1}$ is proportional to $R^{-1 / 2}, V^{-1 / 4}, V^{-1 / 2}, G^{-1 / 2}$ and $C_{0}{ }^{1 / 4}$ by analysis of the distribution of the alloying elements or the marginal stability criterion around the tip of a dendrite. ${ }^{13-16)}$ Okamoto et al. reported the following relationship between cooling rate and the arm spacing: ${ }^{16)}$

$$
\lambda_{1}=2 \varepsilon\left\{-\frac{m(1-k) D_{L} C_{0}}{R}\right\}^{\frac{1}{2}},
$$

where $m$ is the liquidus slope $[\mathrm{K} / \mathrm{mass} \%], k$ is the partition coefficient, $D_{L}$ is the diffusion coefficient in the liquid state $\left[\mathrm{m}^{2} / \mathrm{s}\right]$ and $\varepsilon$ is defined as the correction coefficient during the growth of the secondary dendrite arm. Using $D_{L}=1.67 \times$ $10^{-8} \mathrm{~m}^{2} / \mathrm{s}$, which is suggested for a molten iron specimen with 1.0 to $4.0 \% \mathrm{C}$ at $1470^{\circ} \mathrm{C}$ by Hamada, ${ }^{17)}$ we obtain 
estimated values of $R=1.7 \times 10^{4} \mathrm{~K} / \mathrm{s}$ and $V=142 \mathrm{~mm} / \mathrm{s}$. However, the primary arm spacing is affected by the pulse energy as mentioned above. Thus, we assumed that the cooling rate was inversely proportional to the pulse energy and rearranged the relationship between $\lambda_{1}$ and $E_{P}{ }^{1 / 2}$. As shown in Fig. 6(b), $\lambda_{1}$ is roughly proportional to $E_{P}{ }^{1 / 2}$, and a cooling rate of $0.3-2.4 \times 10^{4} \mathrm{~K} / \mathrm{s}$ and a solidification velocity of $56-167 \mathrm{~mm} / \mathrm{s}$ are estimated by eq. (5) from the primary dendrite arm spacing of 2-6 $2 \mathrm{~m}$. The calculated cooling rate appears to be high, but it has been reported that the cooling rate widely varies from $10^{3}$ to $10^{5} \mathrm{~K} / \mathrm{s}$ depending on the laser melting conditions. ${ }^{9)}$ The solid/liquid interface morphology generally changes from a planar to cellular and dendritic interfaces with increasing solidification velocity. It may also change from dendritic to cellular and planar in the case of high-speed solidification. ${ }^{21,22}$ ) Therefore, the solidification may be a transitional period from the dendritic to cellular growth regime even when $V=142 \mathrm{~mm} / \mathrm{s}$. Furthermore, the lamella spacing $\left(\lambda_{E}\right)$ of a eutectic structure is generally proportional to $V^{-1 / 2}{ }^{18-20)}$ The solidification velocity of the ledeburite microstructure was also estimated to be $V=$ $5 \mathrm{~mm} / \mathrm{s}$ in this study using the results of Park et al. ${ }^{18)}$

In addition, a single-phase austenite is observed in every specimen. Therefore, depths of this single phase and the hybrid mixed microstructure were measured individually in the case of pulse energies from 8 to $12 \mathrm{~J}$. No significant changes are observed in the austenite phase, whereas the depth of the mixed microstructure was approximately proportional to the pulse energy as shown in Fig. 7. A planar interface may be obtained at a solidification velocity of $\mathrm{m} / \mathrm{s}$ order, where the apparent partition coefficient $(k)$ increases and approaches unity. In this experiment, it is difficult to obtain a planar interface because of low solidification velocity of $V=142 \mathrm{~mm} / \mathrm{s}$. Therefore, this austenite single phase may have formed during the transition to the dendritic interface.

\subsection{Effect of microstructure on hardness}

The distribution of the Vickers hardness from the melted layer toward the substrate on a longitudinal section is summarized in Fig. 8 for the specimen melted with a travel

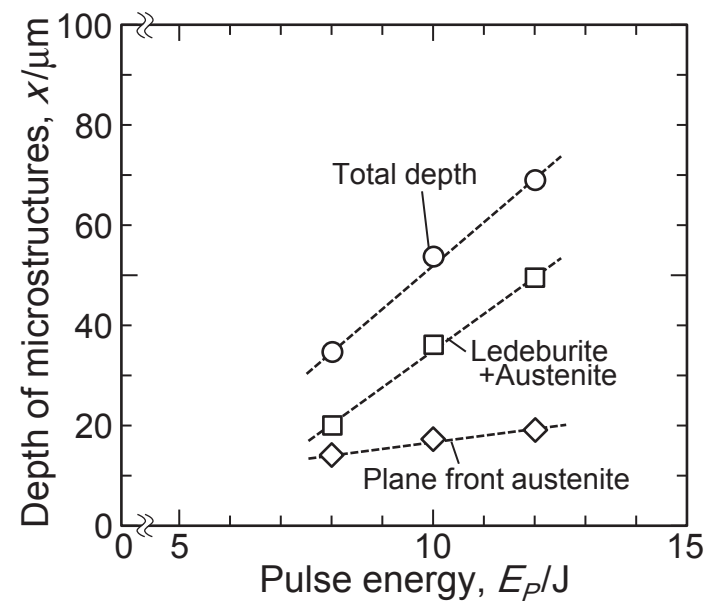

Fig. 7 Relationship between the pulse energy and the depth of each melted microstructure with a travel speed of $1.0 \mathrm{~mm} / \mathrm{s}$ and a pulse frequency of $25 \mathrm{~Hz}$. speed of $1.0 \mathrm{~mm} / \mathrm{s}$, a pulse energy of $12 \mathrm{~J}$, a pulse frequency of $25 \mathrm{~Hz}$ and a pulse duration of $2.0 \mathrm{~ms}$. The hardness was measured along 10 lines at regular intervals of $100 \mu \mathrm{m}$, each of which is plotted with a different symbol. The hardness is 650 to $850 \mathrm{HV}$ near the surface, and then decreases as with increasing depth below the surface of the substrate. However, some hardness values are significantly higher. Since the interface of the melted layer was highly indented, the depth was standardized by the depth of melting corresponding to each measurement line as shown in Fig. 9. Furthermore, the hardnesses of the specimens melted with pulse energies of 8 and $10 \mathrm{~J}$ are also plotted in Fig. 9. The hardness varied from 450 to $900 \mathrm{HV}$ in the melted layer in every specimen, whereas it is $200 \mathrm{HV}$ in the substrate, corresponding to that of the ferrite-graphite microstructure. Some regions have significantly high hardnesses from 900 to $1000 \mathrm{HV}$, as indicated by symbols (A) to (C) in Fig. 9. Therefore, the microstructure was observed in these regions as shown in Fig. 10. It is found that regions (A) to (C) consist of martensite in the vicinity of the interface between the melted layer and substrate. This indicates that the hard martensite was crystallized by the high cooling rate and the rapid diffusion of carbon near the spheroidal graphite.

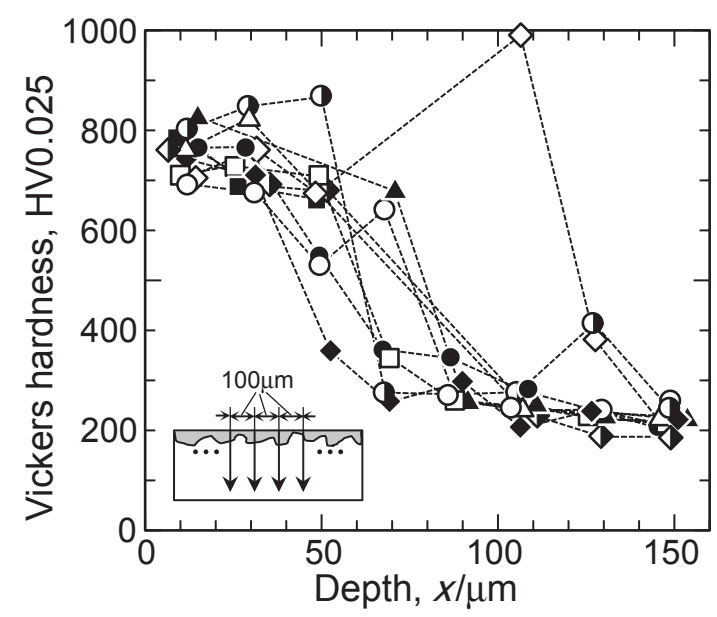

Fig. 8 Distribution of hardness as a function of depth on the cross-sectional solidified layer obtained with a travel speed of $1.0 \mathrm{~mm} / \mathrm{s}$, a pulse power of $12 \mathrm{~J}$ and a pulse frequency of $25 \mathrm{~Hz}$.

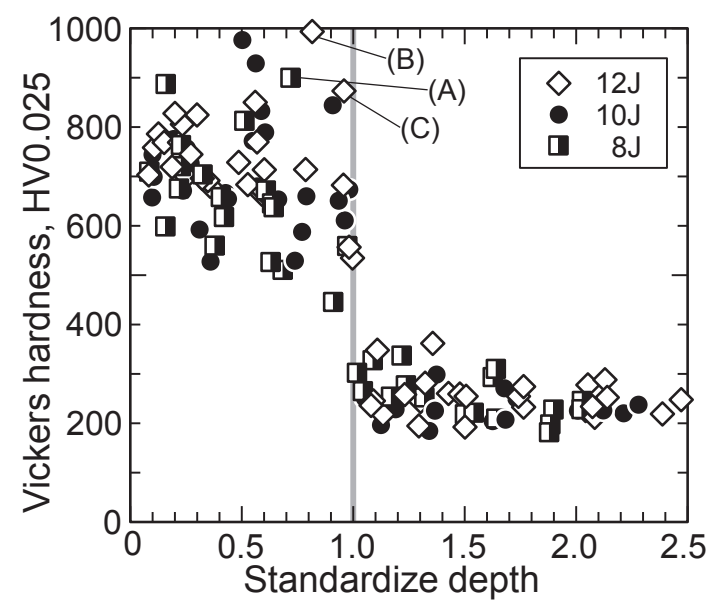

Fig. 9 Distribution of hardness as a function of depth standardized by each melted depth for specimens subjected to pulse powers of 8,10 and $12 \mathrm{~J}$. 

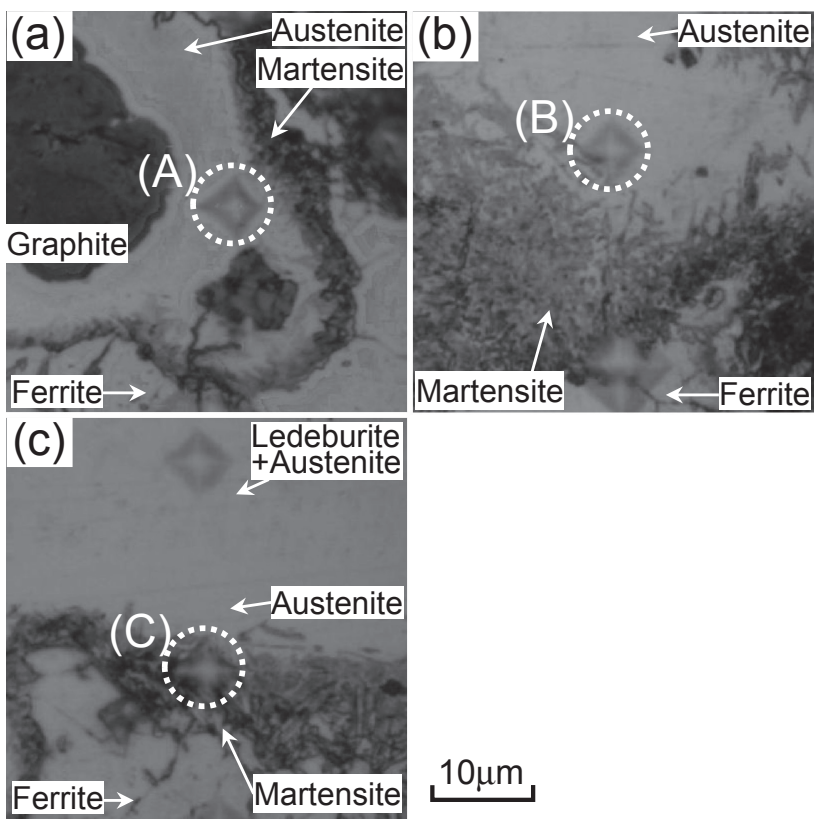

Fig. 10 Microstructures of areas with higher hardness indicated by (A), (B) and (C) in Fig. 9.

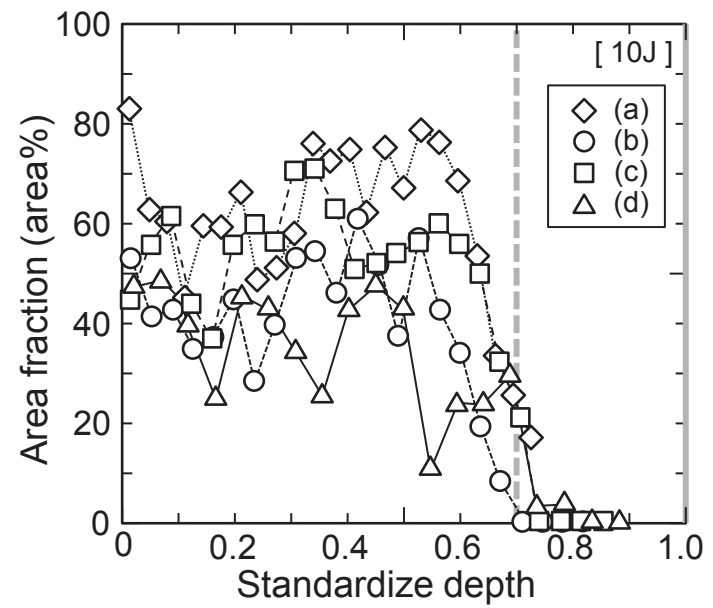

Fig. 11 Distribution of area fraction of ledeburite in the melted layer with a travel speed of $1.0 \mathrm{~mm} / \mathrm{s}$, a pulse power of $10 \mathrm{~J}$ and a pulse frequency of $25 \mathrm{~Hz}$.

The hybrid austenite and ledeburite eutectic structure also has high hardness. Therefore, we assumed that the ledeburite structure contributed to the increased hardness, and measured the area fraction of ledeburite. Figure 11 shows the area fraction of ledeburite in four regions of a specimen subjected to a pulse energy of $10 \mathrm{~J}$. Figure 12 also presents the microstructures and images binarized by a threshold value in the four regions. The area fraction of the eutectic structure increases to about $80 \%$ near the surface. In addition, the fraction of ledeburite appears to increase near the spheroidal graphite as shown in Figs. 4(b) and 5(c). The carbide forms near the melted layer/substrate interface, and its precipitation increased the hardness.

To quantitatively evaluate the effect of the volume fraction of the eutectic structure on the hardening, we estimated the hardness from the eutectic structure and a mixture rule. Since a mixture rule has not established for hardness, the compressive strength was adopted instead of hardness. Many
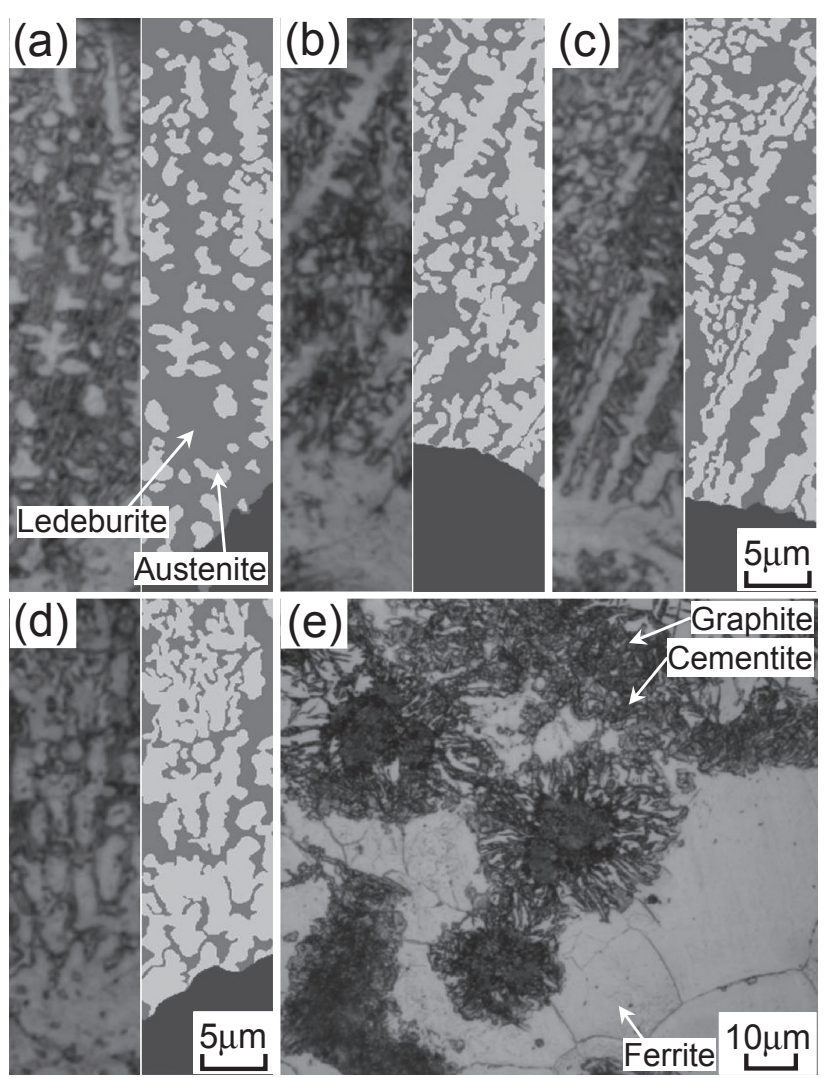

Fig. 12 (a), (b), (c) and (d) are photographs and binarized images of the a ledeburite-austenite hybrid structure in Fig. 11 and (e) precipitated carbide near spherical graphite induced by the thermal effect.

researchers have reported a mixture rule for compressive strength (eq. (6), ${ }^{23)}$ eq. $(7)^{24)}$ and eq. $(8)^{25)}$ ), and we used the equation of Bache (eq. (6)) for the estimation.

$$
\begin{aligned}
\sigma_{C} & =\sigma_{1}^{(1-V f)} \cdot \sigma_{2}^{V_{f}} \\
\frac{1}{\sigma_{C}} & =\frac{1-V_{f}}{\sigma_{1}}+\frac{V_{f}}{\sigma_{2}} \\
\sigma_{C} & =\sigma_{2} \cdot\left\{V_{f}+m\left(1-V_{f}\right)\right\}
\end{aligned}
$$

Here $\sigma_{\mathrm{C}}, \sigma_{1}$ and $\sigma_{2}$ are the compressive strengths of the composites, the matrix phase and the second phase, respectively, $V_{f}$ is the volume fraction of the second phase and $m$ is the ratio of the Young's modulus between the matrix phase and the second phase. Since ledeburite consists of $34 \mathrm{vol} \%$ austenite $(550 \mathrm{HV})$ and $66 \mathrm{vol} \%$ cementite $(1340 \mathrm{HV})$, the hardness of ledeburite was estimated to be 990 HV. From the microstructure in Fig. 4(c), we assumed that the cellular austenite was distributed in the ledeburite phase, and we calculated the hardness using eq. (6) with the area fraction instead of the volume fraction. In Fig. 13, the measured Vickers hardnesses are presented as solid symbols and the calculated values are presented as open symbols. The hardness is estimated to be $550 \mathrm{HV}$ in the austenite single phase and 600 to $900 \mathrm{HV}$ in the hybrid region with austenite and ledeburite structures. The measured and calculated values are similar, which indicates that the Vickers hardness of hybrid phases can also be estimated by the mixture rule of the compressive strength and the hardness of each phase. Finally, the hardness of the melted layer for all specimens is summarized in Fig. 14, where depths were standardized by the melted depth. Three particular regions can be seen in 


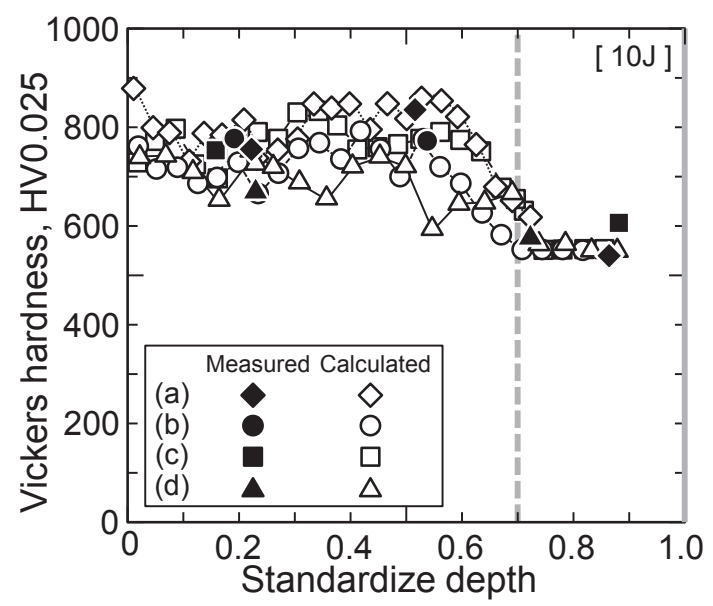

Fig. 13 Distribution of hardness estimated from the area fraction of ledeburite and a comparison with the experimental data in Fig. 11.

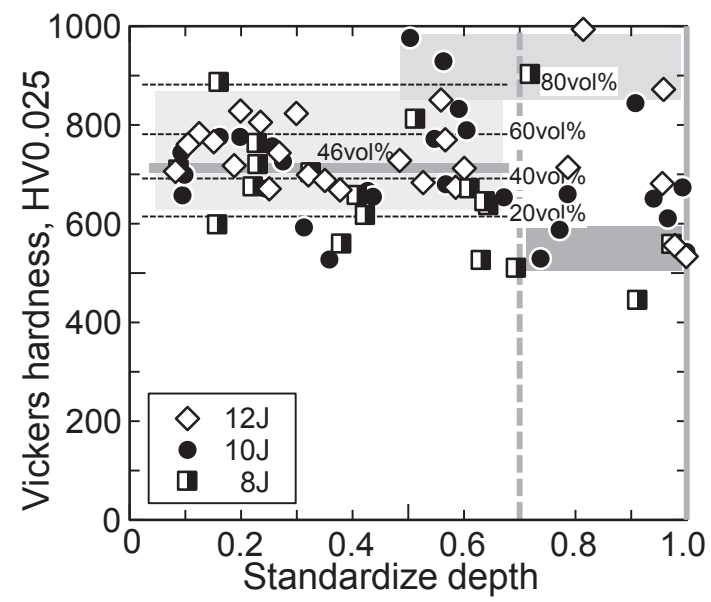

Fig. 14 Distribution of hardness in the melted layer and its relationship with the area fractions of martensite, austenite and ledeburite microstructures.

Fig. 14. First, there is a region with a hardness of 900 $1000 \mathrm{HV}$ (standard depth of approximately 0.5 to 1.0 ), which consists of martensite containing high carbon content diffused from the spheroidal graphite. Second, there is a region with a hardness of $550 \mathrm{HV}$ (standard depth of 0.7 to $1.0)$, which consists of single-phase austenite. Finally, there is a region with a hardness of 600-900 HV (standard depth of 0 to 0.7 ), which consists of a mixture of ledeburite and dendritic or cellular austenite. Therefore, the laser surface melting process can improve the hardness of cast iron, even when it contains a ferrite matrix, and the surface hardness can be predicted from the fractions of ledeburite and austenite phases. If the relationship between the microstructure and the hardness is clarified, it will contribute to predicting the carbide concentration, to predicting the effect of carbon and other alloying elements on surface properties and finally to microstructure design by laser glazing or laser alloying.

\section{Conclusion}

Laser surface melting treatment was performed on spheroidal graphite ferrite-matrix cast iron, the microstructural development was investigated and the improvement of the hardness without the addition of an alloying element was evaluated in relation to the solidified microstructure. Our main findings are as follows.

(1) The surface of the cast iron is melted and rapidly solidified to a depth of $100 \mathrm{~mm}$ order when subjected to laser surface melting, and the melted depth increases with increasing pulse energy.

(2) The melted layer consists of three regions: a martensite phase at the interface of substrate, single-phase austenite and an austenite-ledeburite hybrid structure.

(3) A cooling rate of $0.3-2.4 \times 10^{4} \mathrm{~K} / \mathrm{s}$ is estimated by measurement of the primary dendrite arm spacing under ourexperimental conditions.

(4) A hardness of 600-900 HV was obtained at the melted layer, which was estimated from the fractions of austenite and ledeburite.

\section{Acknowledgement}

This research was supported by JSPS KAKENHI Grants Numbers JP26289281, JP15K14196, JP15H04134.

\section{REFERENCES}

1) Handbook of Foundry Engineering (Japan Foundry Engineering Society, Maruzen, 2002) pp. 221-363.

2) H.T. Angus: Cast Iron, Physical and Engineering Properties (Butterworths, London, 1976) Chapter 1.

3) C.H. Chen, C.J. Altstetter and J.M. Rigsbee: Metall. Trans. A 15 (1984) 719-728.

4) E.V. Locke and R.A. Hella: IEEE J. Quantum Electron. 10 (1974) 179185.

5) F.D. Seaman and D.S. Gnanamuthu: Met. Prog. 108 (1975) 67-74.

6) H. Ogino and T. Yamaguchi: Shinku 56 (2013) 315-321.

7) H. Matsuyama and H. Shibata: Mech. Eng. J. A 58 (1992) 661-667.

8) K. Takayanagi and Y. Kazuyama: Ind. Technol. Res. Hokkaido Division 11 (1998) 172-175.

9) K.Y. Benyounis, O.M.A. Fakron, J.H. Abboud, A.G. Olabi and M.J.S. Hashmi: J. Mater. Process. Technol. 170 (2005) 127-132.

10) J. Grum and R. Šturm: Mater. Charact. 37 (1996) 81-88.

11) K.F. Alabeedi, J.H. Abboud and K.Y. Benyounis: Wear 266 (2009) 925-933.

12) J.H. Abboud, K.Y. Benyounis, A.G. Olabi and M.J.S. Hashmi: J. Mater. Process. Technol. 182 (2007) 427-431.

13) D.J. Hunt: Solidification and casting of metals (Metals Society, London, 1979) p. 1.

14) W. Kurz and D.J. Fisher: Acta Metall. 29 (1981) 11-20.

15) R. Trivedi: J. Cryst. Growth 49 (1980) 219-232.

16) T. Okamoto and K. Kishitake: J. Cryst. Growth 29 (1975) 137-146.

17) K. Hamada, K. Sasaki, K. Oda and Y. Ono: Tetsu-to-Hagané 66 (1980) S156.

18) J.S. Park and J.D. Verhoeven: Metall. Mater. Trans. A 27 (1996) 23282337.

19) P. Magnin and W. Kurz: Metall. Trans. A 19 (1988) 1955-1963.

20) M.P. Wilkinson and A. Hellawell: Brit. Cast Iron Res. Assoc. J. 11 (1963) 439-450.

21) M. Carrard, M. Gremaud, M. Zimmermann and W. Kurz: Acta Metall. Mater. 40 (1992) 983-996.

22) T. Umeda, T. Okane and W. Kurz: Acta Mater. 44 (1996) 4209-4216.

23) H.H. Bache: Proc. RILEM Int. Symp., Testing and Design Methods of Lightweight Aggregate Concretes, Budapest, (1967) p. 9.

24) C. Ramos and S.P. Shah: J. Mater. 7 (1972) 380-387.

25) J. Murata and G. Kamiyama: Ann. Rep. Cement 22 (1968) 223-225. 